\title{
O Atendimento às Adolescentes em Conflito com a Lei: em Foco as Propostas Educacionais no Rio Grande do Norte ${ }^{1}$
}

\author{
The Assistance of Female Adolescents in Conflict with the Law: a Focus on \\ Educational Proposals in Rio Grande do Norte
}

\section{La Atención a las Adolescentes en Conflicto con la Ley: las Propuestas Educativas en Rio Grande do Norte}

\author{
Rocelly Dayane Teotonio da Cunha \\ Universidade Federal do Rio Grande do Norte, Brasil \\ rocellycunha@hotmail.com \\ Ilana Lemos de Paiva \\ Universidade Federal do Rio Grande do Norte, Brasil \\ ilanapaiva@hotmail.com
}

\section{Resumo}

O presente estudo visa discutir as propostas educacionais voltadas para as adolescentes em cumprimento de medidas socioeducativas, no estado do Rio Grande do Norte (RN), do período de 1979 a 2014. Para a realização desta pesquisa, utilizou-se a história oral temática e análise documental. A partir de um roteiro semiestruturado, foram entrevistados oito profissionais que atuaram/atuam nas três unidades de internação feminina identificadas: Granja Santana, Instituto Padre João Maria e o Centro Educacional Padre João Maria (CEDUC). A análise documental foi realizada a partir de documentos da Fundação dos Direitos da Criança e do Adolescente (FUNDAC), CEDUC e Monografias do Departamento de Serviço Social da UFRN. A análise do material coletado esteve apoiada nos aspectos teóricos da teoria marxiana e na perspectiva feminista da divisão sexual do trabalho. Foram identificados três tipos de propostas educacionais: a educação baseada nos valores cristãos, a educação pelo trabalho e a socioeducação. Os dados evidenciam que as propostas educacionais, desenvolvidas ao logo de 35 anos de atendimento no estado potiguar têm sido executadas com base na naturalização do feminino.

Palavras-Chave: Adolescência; Gênero e Socioeducação.

\section{Abstract}

This study aims to discuss the educational proposals geared for adolescent girls who are under socio-educational custody, in the state of Rio Grande do Norte (RN), in the period from 1979 to 2014. In this research, we recurred to oral thematic history and documentary analysis. Following a semi-structured plan, we interviewed eight professionals who worked or still work in one of the three female wards identified as: Granja Santana, Instituto Padre João Maria [Father João Maria Institute] and Centro Educacional Padre João Maria [Father João Maria Educational Center] (CEDUC). The documentary analysis was performed with documents from the Fundação dos Direitos da Criança e do Adolescente [Children and Adolescents Rights Foundation] (FUNDAC), the CEDUC, and from Monographs from the Department of Social Services of the Universidade Federal do Rio Grande do Norte [Federal University of Rio Grande do Norte] (UFRN). The data analysis was supported by the theoretical aspects of the Marxian theory and the feminist perspective on the sexual division of labor. Three types of educational proposals were identified: 
education based on Christian values, education for work and socio-education. The data show that educational proposals, developed along 35 years of social service in Rio Grande do Norte, have been performed on the basis of the naturalization of feminine.e.

Keywords: Adolescence; Gender and Socio-Education.

\section{Resumen}

Este estudio tiene como objetivo discutir las propuestas educativas dirigidas a las adolescentes en cumplimiento de las medidas socio-educativas, en el estado de Río Grande del Norte (RN), en el período de 1979 a 2014. Para esta investigación, se utilizó la historia oral tamática y el análisis documental. A partir de una guión semiestructurado, se entrevistaron ocho profesionales que actuaron / actúan en las tres unidades de internamiento femeninas identificadas: Granja Santana, Instituto Padre João Maria y el Centro Educativo Padre João Maria (CEDUC). El análisis documental se realizó a partir de documentos de la Fundación de los Derechos de la Infancia y del Adolescente (FUNDAC), CEDUC y Monografías del Departamento de Servicio Social de la UFRN. El análisis del material recogido se basa en los aspectos teóricos de la teoría marxiana y en la perspectiva feminista de la división sexual del trabajo. Se identificaron tres tipos de propuestas educativas: la educación basada en los valores cristianos, la educación para el trabajo y la socioeducación. Los datos muestran que las propuestas educativas, desarrolladas a lo largo de 35 años de atención en el estado de Río Grande del Norte, han sido ejecutadas sobre la base de la naturalización de lo femenino.

Palabras-Clave: Adolescencia, Género y Socioeducación.

\section{Introdução}

É inegável que mulheres e homens não ocupam posições igualitárias nas sociedades. Exemplos dessa desigualdade aparecem desde cargos e salários inferiores para mulheres a regras morais que as definem como boas ou más (SAFFIOTI \& ALMEIDA, 1995). Sabemos que, mesmo após as conquistas históricas dos movimentos feministas, as desigualdades entre os sexos se encontram latentes em pleno século XXI. No Brasil, marcas dessa desigualdade nos remetem à formação das relações sociais instituídas desde o período colonial. As circunstâncias desse período, como projeto europeu aristocrata e escravocrata, apresentaram-se como elementos decisivos na vida das mulheres, até os dias atuais (SAFFIOTI, 1979).

Ao analisar a história social da infância e adolescência no país, percebemos inúmeras referências a essa questão. Exemplo disto são as distintas condições relativas aos padrões de socialização e hábitos na família, na escola, nas ruas, para meninas e meninos. Às crianças e às adolescentes do sexo feminino, geralmente, foram-lhes destinadas brincadeiras associadas às atividades domésticas e ações estritamente vinculadas à vida privada (MINELLA, 2006). A persistência dessa configuração deve-se à divisão sexual do trabalho que, por meio dos princípios da separação e da hierarquia, rebaixa o gênero ao sexo biológico e reduz os papéis sociais às diferenças sexuais como um destino natural da espécie. Inevitavelmente, essas condições se reproduzem em diversos espaços da vida social, e os espaços de responsabilização à adolescente autora de ato infracional não se isenta disto. Estudos como o de Silva (2013) e Fachinetto (2008), sobre 
jovens das classes populares, têm demonstrado especificidades de gênero nas relações da vida social, não ocorrendo de forma divergente no campo das medidas socioeducativas. Em pesquisa sobre as vulnerabilidades masculinas, Silva (2013) menciona que, os garotos no processo de socialização são destinados a desenvolver habilidades assertivas naturais do homem. Dentre estas, são primordiais o alheamento aos sentimentos, à intolerância ao diferente, e a consequente incorporação de estereótipos tradicionais. $\mathrm{O}$ que ocasiona a desvalorização das mulheres e a reprodução histórica de opressão ao sexo feminino.

Ressalta-se que este estudo não toma como base o conceito de Gênero como exclusivo para tratar a dominação em relação às mulheres ao longo dos anos. Prefere-se utilizar a categoria das relações de gênero ou divisão sexual do trabalho sem uma ruptura com a ideologia do patriarcado. Posto que, ao adotar a ideologia do patriarcado, ao contrário da utilização do conceito de gênero, evidenciam-se as estruturas de desigualdades sociais entre os sexos e, deixa-se claro, o vetor exploração-dominação discutido por Safiotti (2004).

A virilidade como elemento norteador das ações masculinas, e a submissão da mulher, que necessita da proteção deste homem viril, são elementos presentes na realidade do cumprimento de medidas socioeducativas (FACHINETTO, 2008) e também resultam do patriarcado, inserido nos marcos do sistema capitalista, que subordina e explora as mulheres-adolescentes (SAFIOTTI, 2004).

No estado do Rio Grande do Norte, a institucionalização de adolescentes do sexo feminino se desenvolveu concernente a esta lógica. Desde a reestruturação da capital, Natal, no período republicano, planejaram-se ações de atendimento a meninas em situação de pobreza. Sob a égide do processo da higienização da sociedade brasileira, que implicava na intervenção social autoritária, com vistas a controlar a vida pública e privada (MACHADO, LOUREIRO \& MURICY, 1978), preocupou-se, desde cedo, em propor a chamada reeducação das adolescentes, de forma a prevenir transgressões que infringissem o exercício dos papéis sociais destinados às mulheres. Com intuito de desvelar a história da execução do atendimento educacional destinado às adolescentes autoras de atos infracionais no RN, resgata-se e discute-se, a partir deste estudo, como se desenvolveram as propostas educacionais das unidades de privação e restrição de liberdade feminina no estado potiguar, desde a criação da primeira instituição destinada às meninas, no ano de 1979, até os dias atuais.

\section{Método}

$\mathrm{O}$ presente estudo fundamentou-se em uma abordagem qualitativa. Os instrumentos metodológicos utilizados foram a história oral temática e a análise documental. A história oral temática é uma técnica que quase sempre equivale ao uso da documentação oral da mesma forma das fontes escritas. Por partir de uma temática específica, não privilegia a subjetividade do entrevistado, mas foca no esclarecimento de pessoas sobre algum evento definido (MEIHY, 1988).

Foram entrevistados oito profissionais que atuaram e/ou atuam nas unidades femininas vinculadas à Fundação Estadual dos Direitos da Criança e do Adolescente (FUNDAC), que é uma instituição vinculada ao Estado e responsável pelo acompanhamento da execução das medidas socioeducativas em meio fechado. Realizaram-se sete entrevistas presencialmente e uma por meio de um software de comunicação via internet, tendo em vista que uma das entrevistadas estava residindo no estado de Maine (EUA), no 
período da realização da pesquisa. Além disso, foram analisados documentos (relatórios e monografias) referentes às instituições. Os critérios de inclusão para a amostra neste estudo foram: ter exercido ou ainda estar em exercício como profissional das unidades femininas de responsabilização ao ato infracional, contando desde a primeira instituição criada no estado do Rio Grande do Norte (RN), e consentir responder ao roteiro de pesquisa proposto para o resgate histórico do atendimento nas referidas instituições. As entrevistas foram individuais e registradas em áudio e, posteriormente, transcritas e enviadas aos profissionais entrevistados para releitura e eventual alteração. Os dados foram analisados a partir dos procedimentos da história oral temática: transcrição e textualização. A análise ainda tomou como referencial teórico a teoria marxiana e a perspectiva feminista da divisão sexual do trabalho, conforme estudos das autoras Hirata e Kergoat (2007). A partir da apreensão dos dados, apresenta-se, inicialmente, um breve histórico das instituições de atendimento, após, analisa-se como se desenvolveram as propostas educacionais de cada uma delas.

\section{Um Breve Histórico das Instituições de Atendimento: do Projeto Salvacionista à Socioeducação}

Ao analisarmos a trajetória das políticas para infância e adolescência, vimos que a partir de 1964, no Brasil, a assistência à infância passou a ser de competência do governo militar. Esse governo via, na questão do chamado menor, um problema da Doutrina de Segurança Nacional e Desenvolvimento, sendo, portanto, objeto de sua intervenção e normalização (RIZZINI \& PILOTTI, 2009). Foi assim que se criou a Fundação Nacional do Bem-Estar do Menor (FUNABEM) e a Política Nacional do Bem-
Estar do Menor (PNBEM), às quais coube conduzir as questões relativas às políticas para crianças e adolescentes no Brasil. Nesse contexto, no ano de 1979, é sancionado o Novo Código de Menores que objetivava, enquanto legislação, a defesa dos direitos das crianças e adolescentes. No entanto, trazia a noção do chamado menor em situação irregular que enquadrava a população infanto-juvenil pobre numa espécie de patologia social (RIZZINI, 1993) e, assim, junto à FUNABEM e PNBEM favoreceram a internação em larga escala, no país inteiro (RIZZINI \& PILOTTI, 2009). Foi nesse período que, em Natal, o Instituto Padre João Maria passou por mudanças estruturais e reiniciou o seu atendimento.

O Instituto Padre João Maria (IPJM), foi criado em 1912, com a denominação de Asilo de Mendicidade Padre João Maria. Sendo asilo objetivou atender mulheres, homens, crianças e idosos em situação de rua. A partir de 1979, recebeu a denominação de Instituto e ficou vinculado como um órgão da Fundação do Bem-Estar do Menor do Rio Grande do Norte (FUNBERN) (OLIVEIRA \& ARAÚJO, 1979). Com base na Política de Atendimento à adolescente, conforme determinação do Código de Menores (1979), o Instituto passou a atender especificamente as adolescentes consideradas em situação irregular, notadamente aquelas que, por situação da pobreza, estavam abandonadas, carentes ou por envolvimento com a prostituição $^{2}$ e o uso de drogas (CENTRO EDUCACIONAL PADRE JOÃO MARIA, 2009).

A criação do IPJM se deu com objetivos marcados pela onda de higienização social, presente no Brasil, desde o início da república. Sendo assim, a adolescente que por quaisquer que fosse os motivos comercializasse o corpo, ou o fizesse para fins de satisfação pessoal deveria ter como destino instituições preparadas para reeducá- 
las. Com isso, o Instituto Padre João Maria, com metodologia educacional a fim de recuperar as adolescentes de tais situações, focou-se no trabalho manual, confecção de artesanatos e outros exemplos de atividades consideradas femininas.

No atendimento a essas adolescentes, as posturas divergentes àquelas socialmente esperadas para as mulheres também se enquadravam como grande preocupação da FUNBERN. Para tanto, no Instituto Padre João Maria, as adolescentes foram classificadas em duas categorias: as consideradas meninas fáceis e as meninas difíceis. Assim como houve a separação das meninas por critério de honra (virgem e não virgens) nos recolhimentos do Império, na República e no Serviço de Assistência ao Menor (SAM), em diversas instituições do país - a fim de preparar as futuras mães de famílias cristãs e mulheres estimáveis por suas virtudes domésticas (ARANTES, 2009) - em Natal, também houve a necessidade de separá-las e classificá-las.

De acordo com documento do CEDUC (2009), essa separação ocorreu no mesmo ano de 1979. As discussões em torno dessa questão se expressavam como urgência entre os profissionais da FUNBERN. Para eles, as adolescentes usuárias de drogas e/ou que se mantinham com a prostituição não eram exemplos de posturas adequadas e, devido a isso, não poderiam influenciar as outras adolescentes que, por decorrência do abandono da família, encontravam-se na unidade do Instituto. Assim, criou-se a Granja Santana, uma instituição coordenada por freiras da Congregação Filhas de Sant'ana. Esse novo órgão, também ligado à FUNBERN tinha a finalidade de atender às adolescentes do Instituto, encaminhadas por critério de classificação: mantinham vícios e apresentavam posturas agressivas e ameaçadoras, portanto, posturas consideradas inadequadas para mulheres (CEDUC, 2009).
Para profissionais que atuaram na Granja Santana, a FUNBERN acreditava que essa instituição deveria atender às adolescentes partindo de uma proposta diferente do Instituto. $\mathrm{O}$ objetivo desta unidade era desenvolver um projeto que se considerava diferencial no aspecto educacional, especialmente para as adolescentes em que o atendimento no Instituto Padre João Maria não estava tendo efeito. A proposta era de salvação dessas meninas, que vivendo nos chamados vícios precisavam de uma atenção específica.

No entanto, a proposta do atendimento na Granja Santana não durou muito. No mesmo ano, 1979, com apenas um semestre de funcionamento das atividades, o serviço foi extinto devido ao desligamento das freiras que coordenavam a unidade e a substituição do secretário da Secretaria de Assistência Social do período no RN. Com isso, as adolescentes retornaram para o IPJM, que mantinha o atendimento para as adolescentes em situação de abandono e carência (CEDUC, 2009).

Na década de 1980, o Código de Menores já não atendia às exigências da sociedade nos serviços de proteção à população infantojuvenil. Nessa década, foi possível reunir as principais transformações sociais que ocasionaram no reconhecimento da falência da FUNABEM e das FEBEMs e no surgimento de uma nova política pensada para crianças e adolescentes, como sujeito de direitos (RIZZINI \& PILOTTI, 2009). O Estatuto da Criança e do Adolescente (ECA), por meio da Lei n. 8.069, foi promulgado no ano de 1990, e preconizava a Doutrina de Proteção Integral. Nesse período, no próprio ano de 1980, a FUNBERN passou a denominar-se de Fundação do Bem Estar do Menor (FEBEM), como em outros estados do país.

Nessa fase, o prédio do Instituto, que funcionava numa estrutura de internato, 
necessitou passar por reformas e foi extinto. Com base em dados do CEDUC (2009) as adolescentes foram distribuídas em casas alugadas pela FUNBERN, em Natal e região metropolitana. De acordo com Evangelista (2011), o Instituto Padre João Maria ficou extinto até o final da vigência do Código de Menores. A instituição retornou apenas no ano de 1991, de forma precária, após a promulgação do Estatuto da Criança e do Adolescente (ECA). Em 1993, a unidade foi novamente desativada. Nesse período, considerando que as internas não se caracterizavam na situação autoras de ato infracional grave, segundo a Lei ${ }^{\circ}$ 8069/90 ECA [...] "as internas passaram a ser acompanhadas em suas próprias famílias" (CEDUC, 2009, p. 01).

No ano de 1994, a Fundação Estadual da Criança e do Adolescente (FUNDAC), criada pela Lei 6.682 de 11 de agosto de 1994, substitui a Fundação do Bem-Estar do Menor (FEBEM), no RN, e o Instituto Padre João Maria retoma o atendimento às adolescentes em uma unidade no Complexo do Alecrim, em que houve a junção de quatro diferentes unidades da FUNDAC (CEDUC, 2009).

Com aprovação da resolução $n^{\circ}$ 016/96, o Instituto passou à denominação de Centro Educacional Padre João Maria (CEDUC), nome que permanece até os dias de hoje. De acordo com Evangelista (2011), um convênio da FUNDAC com o Ministério da Justiça, possibilitou, em 24 de setembro de 1998, a inauguração de uma nova unidade para o atendimento das adolescentes. A instituição, a partir disso, destinou-se a atender às adolescentes autoras de atos infracionais de 12 a 18 anos de idade, encaminhadas pelas Varas da Infância e Juventude e os Juízes de Direito das Comarcas de Natal e dos interiores do estado do RN. Baseados na nova política de proteção integral à adolescente, o Centro Educacional inicia a implantação de uma proposta socioeducativa.
Ao analisarmos a historicidade das unidades de atendimento às adolescentes, no estado do RN, identificamos diferentes propostas educacionais que acompanharam o percurso histórico da justiça juvenil voltada para as meninas: a educação baseada nos valores cristãos, a educação pelo trabalho e a socioeducação. A partir da análise dos dados, entendemos que tais propostas não podem ser compreendidas como um contínuo, pois, ao mesmo tempo em que avança, acompanhando as transformações legislativas no campo da política para infância e adolescência, também mantém aspectos das propostas anteriores.

\section{Propostas Educacionais Voltadas para as Meninas em Privação e Restrição de Liberdade no RN}

Conforme dados das entrevistas e da análise documental, abordaremos a Educação baseada nos valores cristãos (Granja Santana), a Educação pelo Trabalho (Instituto Padre João Maria) e a Socioeducação (Centro Educacional Padre João Maria), que acompanharam o percurso histórico da justiça juvenil voltada para as meninas em todo o país. Analisaremos qual o suporte teórico dessas propostas e como, na prática, foram abordadas.

\section{A Educação Baseada nos Valores Cristãos}

Ao fazer uma releitura das propostas educacionais empreendidas para mulheres pela Igreja Católica, no nosso país, de um modo geral, constatou-se que houve várias iniciativas para criações de conventos, recolhimentos e escolas encarregadas de cuidar de jovens mulheres. Dessas iniciativas:

a mais carregada de efeitos para elas foi à criação de uma rede de escolas católicas sob a direção e 
$O$ atendimento às adolescentes em conflito com a lei: em foco as propostas educacionais no Rio Grande do Norte

administração de religiosas. No entanto, as religiosas também ficaram responsáveis pela formação de crianças e adolescentes, mulheres envolvidas com crimes, idosos, além de outras populações que se encontravam em situação de pobreza (LOPES, 2006, p. 170).

No que corresponde ao trabalho com crianças, adolescentes e jovens do sexo feminino, ao longo dos anos, as religiosas prepararam outras mulheres a partir do discurso religioso, com uma profunda visão tradicional do papel social da mulher (LOPES, 2006). No trabalho educacional desenvolvido com as adolescentes institucionalizadas, na Granja Santana, é possível enxergar esse viés histórico, arraigado em todo o país. Em resposta ao questionamento sobre quais eram os objetivos da orientação educacional, uma das entrevistadas descreveu:

O código de Menores tinha uma função muito de isolamento, da privação de liberdade e nós, desse projeto diferenciado, víamos que o contexto de trabalho com essas meninas deveria ser com o trabalho voltado sobre a temática da família. Então, para educarmos essas meninas, nós dizíamos: aqui é a sua casa e nós somos uma família. As irmãs já trabalhavam com mulheres presas. Tinham experiência desde o tempo em que moravam nos Estados Unidos e aqui no Brasil, quando trabalharam na unidade que se chama hoje Instituto Bom Pastor. Então, elas trabalhavam a questão da dignidade e sempre na perspectiva da família. Quanto a atividades pedagógicas mesmo, nós tínhamos muitos cursos. Nós as ensinávamos a cozinhar. Elas fizeram também cursos para confecção de bolsas, costura, cortes de cabelo e cursos de manicure. [Educadora que atuou na Granja Santana] [Entrevista realizada no dia 16 de maio de 2013, Natal, RN].

Essas informações são reforçadas pelo relato da religiosa que administrava essa unidade de atendimento:

Com base na minha experiência nos Estados Unidos, a proposta educativa era basicamente comunicar para menores infratoras o amor e a bondade. Nós tínhamos poucos meios para trabalhar com esse tipo de meninas com problemas de conduta. Havia ausência de atendimento profissional. Lembrome que a Casa era muito longe das coisas e para conseguir até um transporte era coisa muito difícil. Aí no Brasil era muito diferente dos Estados Unidos. Nos Estados Unidos eu era acostumada a trabalhar com muitos profissionais com esse tipo de menina. Eram psicólogos, psiquiatras, da área do serviço social. As meninas eram perturbadas mesmo e precisavam de uma assistência com muitos profissionais, mas não tinham. [Diretora que atuou na Granja Santana] [Entrevista realizada no dia 18 de abril de 2014, Natal, RN].

Percebe-se, a partir dos relatos, que a proposta educacional da referida unidade se baseou, predominantemente, nos valores cristãos, no qual o intuito dessa educação se focava no reforço dos padrões associados à posição socialmente construída para as mulheres. 


\section{A Educação pelo Trabalho}

Como vimos, a FUNABEM, órgão que substituiu o extinto SAM, surgiu com a finalidade de afastar-se das críticas e ser o oposto de seu predecessor. Certos de sua incumbência de atuação para o novo órgão de atendimento aos menores, a FUNABEM deixava evidente seus objetivos legais, no qual destacaremos alguns:

I- Realizar estudos, inquéritos e pesquisas para desempenho da missão que the cabe, promovendo cursos, seminários e congressos, procedendo ao levantamento nacional do problema do menor;

II- Promover a articulação das atividades de entidades públicas e privadas;

III- Propiciar a formação, o treinamento e o aperfeiçoamento de pessoal técnico e auxiliar necessários aos seus objetivos;

VII- Propiciar assistência técnica aos estados, municípios e entidades públicas ou privadas que a solicitarem (LEI N. 4.513/1964, $\left.\operatorname{art.} 7^{\circ}\right)$.

Na década de 1980, era perceptível que a FUNABEM, juntamente com PNBEM, não haviam conseguido os objetivos propostos. Nesse período, a incongruência das finalidades da instituição com a ideologia da Segurança Nacional incidia em discussões sobre quais rumos essas instituições deveriam tomar para não chegar à extinção. Com o intuito de trocar experiências de unidades de atendimento modelos e formar profissionais, a FUNABEM propôs às FEBEMs de cada estado "um intercâmbio de experiências" (SILVA \& LIMA, 1986, p. 24).

Segundo Silva e Lima (1986), foram oferecidos estágios aos técnicos de várias unidades da FUNABEM. Para eles, a troca de experiência entre os profissionais possibilitaria a aprendizagem do modelo de atendimento daquelas unidades padrões para, posteriormente, instituí-las na sua unidade de trabalho. No Rio Grande do Norte, uma das unidades escolhidas para o intercâmbio foi o Instituto Padre João Maria. O campo de estágio foi a Escola Barão de Camargos e a Casa São Francisco, no estado de Minas Gerais, devido às características que se assemelhavam com a unidade do Instituto Padre João Maria. Ambas atendiam adolescentes do sexo feminino com conduta "antissocial e, portanto infratoras ou abandonadas pelos pais ou responsáveis" (SILVA \& LIMA, 1986, p. 25).

A proposta a ser implantada à época deveria se preocupar com uma lógica pedagógica. Afinal, para o Estado nacional, a massa crescente de crianças, adolescentes e jovens marginalizados, somada ao caos no atendimento no interior das unidades, reforçavam a previsão dos prejuízos consideráveis, do ponto de vista socioeconômico e político. Em documento publicado no ano de 1976, a FUNABEM já descrevia a sua preocupação com a questão dos chamados menores. Para essa entidade, a preservação do capital humano (FUNABEM, 1976b) importava diretamente à ideologia do modelo de desenvolvimento adotado, na medida em que afetava o poder nacional (VOGEL, 2009). O poder nacional seria afetado, à medida que meninas e meninos da nação estivessem despreparados para a lógica do trabalho. Com essa pretensão, a FUNABEM pretendia disseminar a proposta de Educação pelo Trabalho, implantada pelo pedagogo Antônio Carlos Gomes da Costa, desde 1976 (SILVA \& LIMA, 1986). Com a realização do estágio na Escola Barão de Camargos, escola em que o pedagogo ocupava o cargo de diretor, a psicóloga retornou ao Instituto Padre João Maria e 
iniciou a implantação da proposta educacional vivenciada.

Na concepção de Costa (1984), ao definir uma proposta baseada na educação pelo trabalho, inicialmente, é necessário destacar a divergência em relação à educação para o trabalho. $\mathrm{Na}$ primeira perspectiva, a educanda ou o educando aprende para trabalhar, na segunda, no entanto, a educanda ou educando trabalha para aprender. Para este autor, a Educação pelo trabalho, em linhas gerais, significa educar jovens envolvidos com infrações utilizando o trabalho.

Educar é criar espaços para que o educando, situado concreto e organicamente no mundo, como sujeito e não como objeto, possa empreender ele próprio a construção do seu ser, tanto no nível pessoal, como a nível social (COSTA, 1984, p. 11).

Sendo assim, a educação pelo trabalho é o processo educacional produtivo que objetiva produzir homens conscientes e aptos para o engajamento na classe trabalhadora. Propõe não apenas utilizar a mão de obra dos jovens, mas desenvolver mulheres e homens capazes de serem produtivos e emancipados. Para que assim ocorra, não poderá ser desenvolvida de forma desmembrada da participação da adolescente. A adolescente e/ou o adolescente não deve ser excluído da finalidade do trabalho, da organização e do produto final que esse trabalho resulta: "A proposta pedagógica - Educação pelo Trabalho - deve ser dar de forma participativa, com diálogo e planejamento entre a equipe institucional e as educandas" (SILVA \& LIMA, 1986, p. 28).

São os três princípios básicos desta proposta: "( $\left(1^{\circ}\right)$ A participação do educando na gestão de trabalho; $\left(2^{\circ}\right)$ A participação do educando no produto do seu trabalho; $\left(3^{\circ}\right) \mathrm{A}$ participação do educando no conhecimento relativo ao trabalho realizado" (SILVA \& LIMA, 1986, p. 28).

A partir desses princípios, tentou-se implantar, no Instituto Padre João Maria, uma prática pedagógica, "a qual declara que as educandas e educadores têm participação ativa na construção do plano de ação institucional e na sua execução" (SILVA \& LIMA, 1986, p. 30). A assistente social e a Pedagoga entrevistadas descreveram esse contexto:

A princípio não existia nenhuma atividade de cunho pedagógico, depois, a equipe pensou em realizar com elas trabalhos manuais, tinham algumas monitoras que acompanhavam. Depois de um curso que uma das técnicas fez em Minas Gerais, a equipe conseguiu um convênio em uma fábrica de botões em Parnamirim. Elas colavam aquelas pedras nos botões. Era um convênio, eles vinham buscar as meninas na instituição, depois as deixavam de volta e elas eram remuneradas. Foi muito bom, aí abriram uma caderneta de poupança na Caixa Econômica para elas $e$ a gente administrava, por elas serem menores de idade [Assistente Social que atuou no Instituto Padre João Maria] [Entrevista realizada no dia 23 de setembro de 2013, Natal/RN].

Eu lembro que tinha uma fábrica de botões, a Bonor, era ótimo! $O$ pessoal de lá nos mandavam os botões e as meninas pregavam. E a gente repassava uma parte do dinheiro para elas. Elas ficavam direto dentro de casa, às vezes a mãe passava muito tempo sem vêlas, então, elas mesmas juntavam o dinheiro para comprar coisas para 
$O$ atendimento às adolescentes em conflito com a lei: em foco as propostas educacionais no Rio Grande do Norte

\section{elas [Pedagoga que atuou no Instituto Padre João Maria] [Entrevista realizada no dia 08 de agosto de 2013, Natal/RN].}

Segundo Silva e Lima (1986), o convênio da instituição com a fábrica de botões Bonnor constituía o elemento central da proposta educacional do atendimento às adolescentes. De acordo com as observações in loco realizadas por essas autoras, as adolescentes costuravam botões em cartelas que serviriam à fábrica como mostruários. As adolescentes chegaram a trabalhar no espaço da fábrica, mas logo, passam a trabalhar na própria unidade, que começa a parecer uma mini fábrica. Isso porque, as adolescentes passam a ganhar por produção, sem "contudo, manterem nenhum vínculo empregatício com a Bonnor" (p. 33).

$\mathrm{Na}$ realidade, os princípios da Educação pelo Trabalho logo foram desconsiderados. Segundo as autoras citadas, e reforçado pelas entrevistadas, o desenvolvimento da prestação de serviço para Bonnor descaracterizava qualquer proposta educacional. Pois, na prática, as adolescentes eram meros instrumentos, utilizadas para a produção da fábrica, em um trabalho alienado que nada tinha de emancipador.

Notamos que na instituição essa consciência individualista (classe em si) é repassada e fortalecida no educando. Exemplificamos essa justificativa com o trabalho de botões do Instituto Padre João Maria, onde segundo a instituição é o momento das menores se integrarem umas com as outras. Porém, o que acontece é o aumento do individualismo provocado pela ansiedade e estímulo que recebem de produzirem cada vez mais, aumentando assim a competição entre as educandas, impossibilitando o relacionamento e a capacidade de relacionarem a produção com a forma coletiva que a mesma realiza (SILVA \& LIMA, 1986, p. 38).

Além da prestação de serviço para a fábrica Bonnor, em algumas ocasiões, eram oferecidos para as adolescentes, cursos de Datilografia, de doces e salgados, de pintura de panos de prato. Segundo relato dos profissionais entrevistados, os convênios com empresas eram sempre recebidos com satisfação, pois havia uma preocupação com a ociosidade das adolescentes.

Ao longo dos anos, priorizou-se oferecer no IPJM, cursos como confecção de bolsas, de salgados e doces, pinturas de panos de pratos e artesanatos. Embora, saibamos que essas atividades contenham seus valores na sociedade, a crítica que se empreende aqui é que, quando se trata de mulheres, há uma nítida invisibilidade do empoderamento feminino na perspectiva educacional e profissional. Se analisarmos a perspectiva educativa desenvolvida aos adolescentes do sexo masculino, ao longo dos anos nas unidades masculinas, perceberemos que estes, frequentemente, foram utilizados também como mão de obra barata no setor produtivo capitalista, no entanto, esse destino não se estende às adolescentes na mesma situação, que sofrem uma dupla subordinação (ARANTES, 2009).

Conforme apontam Diogo e Coutinho (2006), são as jovens mulheres as mais excluídas das propostas de qualificação exigidas pela lógica neoliberal, passando por processos ainda mais precários que os homens. Como observado, as regras da dominação de gênero perpassam várias esferas da atividade social (SAFFIOTI, 2004), e não causa surpresa que os mecanismos de exclusão para mulheres sejam encontrados na realidade do atendimento do sistema de justiça juvenil.

Essas questões nos permitem refletir sobre como a ordem neoliberal mantêm e perpetua 
as desigualdades e, consequentemente, os processos de exclusão das mulheres em atividades fora do ambiente doméstico. Segundo Hirata (2002), ao analisar demandas relativas à situação de mulheres, em diversos âmbitos, a perspectiva de que as relações entre homens e mulheres são sexuadas deve ser considerada. Para a autora, essas relações são "relações desiguais, hierarquizadas, assimétricas ou antagônicas de exploração e de opressão entre duas categorias de sexo socialmente construídas" (p. 276). De acordo com Diogo e Coutinho (2006), a inclusão das mulheres na sociedade, em diversos campos da sociedade, respalda-se nas relações de exploração e de opressão do masculino sobre o feminino.

No sistema capitalista, as bases materiais e simbólicas de opressão sobre as mulheres se reforçam (ÁVILA, 2013). De acordo com Fonseca (2000), no modo de produção capitalista, o capital dialoga com o feminino e com o masculino de forma diferenciada. Nesse contexto, discrimina-se a mão de obra utilizada nos postos de trabalho e sexualizam-se as ocupações. Discutindo a divisão do trabalho sob a perspectiva do gênero, Antunes (1999) afirma: "nas áreas onde é maior a presença de capital intensivo, de maquinário mais avançado, predominam os homens. E nas áreas de maior trabalho intensivo, onde é maior ainda a exploração do trabalho manual, trabalham as mulheres" (p. 202). Temos aqui, então, uma estruturação do mundo do trabalho que se configura a partir das relações de classe, com aprofundamentos de precariedade relacionados à raça e gênero (ÀVILA, 2013).

Essa configuração reflete nos processos educacionais que objetivam persistir as desigualdades existentes nessas relações e ensinar aos mais jovens os comportamentos adequados para o exercício dos papéis sociais (SAFFIOTI, 1987). Na proposta pedagógica do IPJM, a educação pelo trabalho expressou como essas questões se desenvolveram na realidade do atendimento no RN. Ainda que a proposta, segundo Costa (1984), pretendesse ser diferente da educação alienada para o trabalho, sendo desenvolvida a partir da gestão participativa e emancipatória das adolescentes, na prática, pelo menos no âmbito desta pesquisa, essa proposta reforçou a exploração da força de trabalho feminina, em detrimento de uma ação transformadora.

Além disso, a escolha do tipo de trabalho, instituído pelo convênio com a fábrica de botões, indica que, quando se pensa na relação das mulheres com o trabalho, predomina o direcionamento delas para a segmentação ocupacional nas áreas de serviços pessoais, domésticos, comércio de mercadorias, dentre outros ${ }^{3}$. Concorda-se com Diogo e Coutinho (2006) quando afirmam que essa questão tem raízes históricas, datadas do início do século passado, com o surgimento da mãe cívica. Há um reforço da figura materna como a responsável pela preparação física, moral e intelectual das filhas e filhos (RAGO, 1997). Utilizando a premissa da velha naturalidade, enfatizavam-se as qualidades das mulheres para líderes domésticas.

\section{A Socioeducação}

A promulgação do ECA, que preconizou a Doutrina da Proteção Integral em detrimento da Doutrina da Situação Irregular, nos anos 1990, enfatizou o direito da criança e do adolescente a serviços sociais, e propôs transformações profundas no sistema de justiça juvenil. A partir dessas transformações, a proposta de atendimento aos adolescentes, do sexo feminino e masculino, em cumprimento de medidas socioeducativas, passou a priorizar a perspectiva educativa (BASÍLIO \& KRAMER, 2011). Com intuito de abandonar as velhas práticas punitivas, o ECA causou uma ruptura ético-política e propôs a 
aplicação de medidas socioeducativas como forma de responsabilização e transformação da realidade das jovens e dos jovens envolvidos com infrações.

Nesse contexto, as ações pedagógicas baseadas nas ideias da Educação Popular, originadas entre os anos 1950 e 1960 (BEISIEGEL, 1989), tomaram novas evidências no Brasil. $O$ cenário do acirramento das desigualdades sociais, resultado das consequências do golpe militar de 1964, até medidas de aceleração da economia - o famoso 'milagre' - provocou, no Brasil, um período de maior crise de sua história afetando diretamente a população infanto-juvenil (OLIVEIRA, 2007). Com a aprovação de uma política integrada na perspectiva dos direitos humanos, o ECA e sua doutrina propunham ultrapassar a reprodução do discurso menorista e fundar, na assistência à infância e adolescência, ações educacionais que, de fato, promovessem a transformação social (BASÍLIO \& KRAMER, 2011). Assim, as concepções da Educação Popular ou Social começam a se tornar direcionamento dos serviços de atendimento a crianças e adolescentes consideradas em situação de vulnerabilidade social.

A educação popular ou social se apoia na educação dialógica do teórico brasileiro Paulo Freire e tem a finalidade de construir um projeto educacional mais justo, solidário e humano. Nessa perspectiva, o processo educativo é considerado mediador essencial para mudança de padrões de conduta, modos de vida, atitudes e relações sociais. Propôsse, a partir desta perspectiva, a tratar os educandos de forma integrada aos contextos e vivências de sua própria realidade social (WERTHEIN, 1985). Segundo Werthein (1985), a realidade social, inclusive, é o ponto de partida para o processo educacional, que, através da sua disseminação, volta-se a ele, para, enfim, transformá-lo.
$\mathrm{Na}$ busca dos caminhos possíveis para a reorientação dos valores, condutas e novas perspectivas para a transformação social, com base na Educação Popular, surge a proposta da educação social de rua que se baseou na Pedagogia da Presença e estava voltada para a população em situação de rua (OLIVEIRA, 2007). Nessa perspectiva, o processo educacional integra-se à participação da família e da comunidade.

Com a aproximação das realidades das crianças sobreviventes nas ruas, e com os adolescentes dentro das unidades de cumprimento de medidas socioeducativas, o foco da educação social de rua é ampliado e essa perspectiva passa a ser trabalhada pelas instituições de acompanhamento das medidas socioeducativas (OLIVEIRA, 2007).

No ano de 2006, a proposta educacional da Educação Social de Rua (ESR), bem como, as concepções pedagógicas e políticas resgatadas da Educação popular, orientaram a formulação dos princípios do Sistema Nacional de Atendimento Socioeducativo (SINASE). Nesse cenário, os princípios da ERS se incorporam à proposta de atendimento no cumprimento de medidas socioeducativas e a proposta educacional para adolescentes envolvidos com atos infracionais deve direcionar esse adolescente a:

atuar como pessoas, cidadãos e futuros profissionais, para que não reincidam na prática de atos infracionais (crimes e contravenções, se cometidos por adultos), garantindo, ao mesmo tempo, o respeito aos seus direitos fundamentais e à segurança dos demais cidadãos (COSTA, 2006, p.24).

Em 2006, com a publicação das diretrizes básicas para o Sistema Nacional de Atendimento Socioeducativo (SINASE), formulado pelo Conselho Nacional dos 
Direitos da Criança e do Adolescente (CONANDA), as unidades e programas que executam as medidas socioeducativas devem se basear na "diretividade; na disciplina como meio; na horizontalidade na socialização das informações entre a equipe multidisciplinar; na organização funcional e espacial para promoção de boas atividades; na participação da família e da comunidade no processo socioeducacional e a formação continuada de profissionais e na diversidade ético-cultural, de gênero e orientação sexual como norteadora para prática pedagógica" (CONANDA, 2006, p. 48 e 49). A prática deveria observar os seguintes pontos:

$\left.1^{\circ}\right) \quad$ Prevalência da ação socioeducativa sobre os aspectos meramente sancionatórios;

$2^{\circ}$ Deve ter o Projeto Político Pedagógico como ordenador de ação e gestão do atendimento socioeducativo; participação dos adolescentes na construção, no monitoramento na avaliação das atividades socioeducativas; respeito à singularidade do adolescente, presença educativa e exemplaridade como condições necessárias e exigência e compreensão na ação socioeducativa (CONANDA, 2006, p.47 e 48).

Vale salientar que, em 2012, é promulgada a Lei $\mathrm{N}^{\circ} 12.594$ que tem o objetivo de instituir oficialmente o SINASE e regulamentá-lo. No Rio Grande do Norte, no entanto, a realidade do cotidiano institucional das unidades de medidas socioeducativas tem expressado outra realidade. As inúmeras irregularidades no âmbito da gestão da FUNDAC, bem como, a omissão do Estado do $\mathrm{RN}$ com relação às violações sofridas por adolescentes de ambos os sexos do Sistema Socioeducativo potiguar, causaram falência dos atendimentos, sobretudo dos direcionamentos educacionais determinado pelo ECA e reforçado pela Lei do SINASE.

De acordo com o Inquérito Civil $\mathrm{n}^{\circ}$ 010/2012, movido pela $21^{\circ}$ Promotoria de Justiça da Comarca de Natal (2014) ${ }^{4}$, há quase dois anos é de público conhecimento a falência da FUNDAC. As interdições parciais dos Centros Educacionais de Caicó e de Mossoró determinadas, devido aos alertas e aos relatórios produzidos pelo Conselho Nacional de Justiça (CNJ), e a interdição do Centro Educacional Pitimbu pela Corregedoria de Justiça do Estado do Rio Grande do Norte, demonstraram a grave situação do Sistema Socioeducativo norterio-grandense. Com efeito da crise do Sistema Socioeducativo potiguar, não poderíamos esperar outro panorama. Com a interdição do CEDUC Pitimbu, ocorrida no dia 13 de março de 2012, por decisão liminar da Vara da Infância e Juventude, e as condições de insalubridade e insegurança do Centro Integrado de Atendimento ao Adolescente Acusado de Ato Infracional (CIAD), constatadas neste mesmo ano, os adolescentes da Grande Natal, submetidos à medida de internação e os inseridos provisoriamente no CIAD, foram encaminhados para outras unidades do sistema. Essa situação trouxe efeitos marcantes para o Centro Feminino.

$\mathrm{O}$ Documento Interinstitucional: irregularidades no sistema socioeducativo, ao fazer um resgate das irregularidades das unidades e da própria gestão da FUNDAC, oferece algumas recomendações, dentre elas nos interessa ressaltar as que provocam mudanças do Centro Educacional Padre João Maria. Tendo em vista a situação de grave crise no que se refere às vagas disponibilizadas pela FUNDAC, sugere-se, conforme consenso dos participantes, que Vossa Excelência determine, como medidas emergenciais, as seguintes providências, 
quais sejam:

disponibilizar vagas imediatas para o cumprimento de medidas socioeducativas de internação, sugerindo-se que o Centro Educacional Padre João Maria destinado ao cumprimento de medidas por adolescentes do sexo feminino passe a receber adolescentes do sexo masculino (quantidade maior) e as adolescentes do sexo feminino sejam remanejadas para outro prédio com estrutura menor, como, por exemplo, o prédio da FUNDAC que fica localizado na Rua Adolfo Gordo, abrindo-se temporariamente vagas para pelo menos 15 (quinze) internações, até que o CEDUC Pitimbu seja desinterditado (DOCUMENTO INTERINSTITUCIONAL, 2002, p. 11).

O prédio da FUNDAC, referido no relatório, não se trata do Centro Educacional Padre João Maria, inaugurado em 1998, conforme descrevemos anteriormente, tratase de outro prédio. No entanto, esse não foi o destino dado às adolescentes. A FUNDAC, atendendo à recomendação do Documento Interinstitucional, transferiu os adolescentes do sexo masculino para a unidade do CEDUC Padre João Maria e o atendimento para as adolescentes passa a ser realizado em uma unidade pertencente à FUNDAC, uma rua ao fundo do CEDUC feminino, no mesmo bairro.

Em anos anteriores, a referida unidade já havia sido utilizada para a realização das atividades referente às medidas de semiliberdade feminina. Fato que não ocorria recentemente, pois, sob a alegação da quantidade inferior de meninas no Sistema Socioeducativo, o CEDUC feminino vem atendendo, no mesmo espaço, a todas as medidas, estando, assim, inconsistente aos procedimentos de execução de medidas determinados pelo ECA e pelo SINASE.

A preocupação de entender as propostas de atendimento para o gênero feminino, no âmbito do Sistema Socioeducativo, advém do fato de que os próprios atores do Sistema de Garantias de Direitos da Criança e do Adolescente, que são em sua maioria homens, também assumem um papel de poder nas relações de gênero. No contexto da execução de medidas socioeducativas, poucas são as abordagens, do ponto de vista legal e de políticas nacionais, sobre essa questão. Não obstante, o SINASE determina, em seu décimo eixo, a necessidade da adequação das propostas pedagógicas às diversidades étnico-raciais, de gênero e de orientação sexual:

Questões da diversidade cultural, da igualdade étnico-racial, de gênero, de orientação sexual deverão compor os fundamentos teóricometodológicos do projeto pedagógico dos programas de atendimento socioeducativo; sendo necessário discutir, conceituar e desenvolver metodologias que promovam a inclusão desses temas, interligando-os às ações de promoção de saúde, educação, cultura, profissionalização e cidadania na execução das medidas socioeducativas, possibilitando práticas mais tolerantes e inclusivas (CONANDA, 2006 p. 55).

$\mathrm{Na}$ prática, poderemos encontrar realidades que invisibilizam as adolescentes e não contribuem para construção de projetos de vida aliados aos valores e respeito às diversidades de gênero e orientação sexual. Assim como a realidade de todas as unidades do RN, no Centro Educacional Padre João Maria (CEDUC), não foi construído um 
projeto político pedagógico que orientasse as ações e o atendimento, o que se mantém até os dias atuais.

Com base nas entrevistas, evidenciou-se que as atividades pedagógicas continuam sendo, predominantemente, manuais e as atividades esportivas não ocorrem com regularidade. Ao questionar sobre qual era a proposta educacional da unidade, após o SINASE, a diretora do CEDUC (do período de fevereiro de 2011 a novembro de 2012) relatou que, logo após a publicação do SINASE (2006), a equipe técnica reuniu-se e realizou um levantamento com as adolescentes do serviço sobre quais atividades pedagógicas elas gostariam de participar.

Quando foi publicado o SINASE nós nos reunimos para elaborar atividades baseadas nos eixos desse documento. Então, fazíamos um levantamento. Elas queriam informática. Não tinha informática, porque a unidade não oferecia computador, na época. A gente, geralmente, tinha material para oficina artesanal, então nós falávamos: vamos fazer artesanatos. Mas, quem dava esses materiais era a oficineira, ou então, para conseguir mais pegávamos uma parte dos lucros de bazares que realizávamos e comprávamos mais e o restante era para elas. Do lucro, $20 \%$ se destinavam a comprar os materiais e $80 \%$ para elas. Todas participavam. Elas gostavam muito de fazer cachorrinho e a vendagem era muito boa [Diretora que atuou Centro Educacional Padre João Maria] [Entrevista realizada no dia 16 de maio de 2013, Natal/RN].

Para a oficineira deste período, as atividades pedagógicas eram escolhidas por serem condizentes com as habilidades femininas, como por exemplo, a pintura. Para essa profissional, nos trabalhos manuais, as adolescentes se sentem mais realizadas, por serem mulheres.

Ao final da realização deste trabalho, observa-se que a situação continua a mesma. Para os técnicos, com a inviabilidade da FUNDAC de financiar as atividades, as oficinas e a estrutura, dentre outros fatores, as atividades tem se limitado, basicamente, à confecção de bijuterias e realização de bazares com o apoio de doadores. Por estar, atualmente, funcionando numa pequena casa, a prática esportiva é inexistente e as rodas de conversas, ou atendimento individuais, acabam ocorrendo em setores inadequados da unidade.

Com base nos dados apresentados, percebe-se que as propostas educacionais da Granja Santana, do Instituto Padre João Maria e do Centro Educacional Padre João Maria, desenvolveram-se com a predominância de atividades que reproduzem as tarefas domésticas e/ou exploram habilidades consideradas naturalmente femininas. Os tipos das atividades pedagógicas e as oficinas profissionalizantes e os discursos que as acompanham, reproduzem, nas três unidades identificadas, os mecanismos de exclusão incidentes sobre as mulheres nas sociedades. Os dados chamam atenção pelas três propostas educacionais acabarem por limitar as possibilidades educativas das adolescentes. Atualmente, sob a alegação da falência do sistema de funcionamento da atual FUNDAC, elas continuam destinadas exclusivamente a trabalhos manuais $\mathrm{e}$ repetitivos, com os quais acreditam serem social e culturalmente identificadas.

A tabela a seguir apresenta o resumo de como se desenvolveram tais propostas nas três unidades de atendimento descritas: 
Tabela 1 - Propostas educacionais das unidades para adolescentes autoras de atos infracionais do Rio Grande do Norte).

\begin{tabular}{|c|c|c|c|c|}
\hline $\begin{array}{c}\text { Unidade de } \\
\text { Atendimento }\end{array}$ & $\begin{array}{c}\text { Proposta } \\
\text { Educacional }\end{array}$ & $\begin{array}{c}\text { Atividades } \\
\text { pedagógicas }\end{array}$ & $\begin{array}{c}\text { Oficinas } \\
\text { profissionalizantes }\end{array}$ & $\begin{array}{l}\text { Atividades } \\
\text { esportivas }\end{array}$ \\
\hline Granja Santana & $\begin{array}{c}\text { Educação } \\
\text { baseada em } \\
\text { valores cristãos }\end{array}$ & $\begin{array}{l}\text { - Aulas sobre } \\
\text { como cozinhar } \\
\text { - Aulas de } \\
\text { alfabetização }\end{array}$ & $\begin{array}{l}\text { - Cursos para confecção } \\
\text { de bolsas, cortes, } \\
\text { costura, cortes de } \\
\text { cabelo, manicure }\end{array}$ & - Nenhuma \\
\hline $\begin{array}{c}\text { Instituto Padre João } \\
\text { Maria }\end{array}$ & $\begin{array}{c}\text { Educação pelo } \\
\text { Trabalho }\end{array}$ & $\begin{array}{l}\text { - Oficinas de } \\
\text { Artesanato } \\
\text { - Aulas de } \\
\text { alfabetização }\end{array}$ & $\begin{array}{l}\text { - Curso de datilografia } \\
\text { - Curso de doces e } \\
\text { salgados } \\
\text { - Curso de pintura de } \\
\text { panos de prato } \\
\text { - Prestação de serviço } \\
\text { para fábrica de botões }\end{array}$ & - Jogos \\
\hline $\begin{array}{l}\text { Centro Educacional } \\
\text { Padre João Maria } \\
\text { (CEDUC) }\end{array}$ & Socioeducação & $\begin{array}{c}\text { - Escolarização } \\
\text { do ensino } \\
\text { undamental I } \\
\left(1^{\circ} \text { ano } 5^{\circ}\right) \\
(2000-2002) \\
\text { - Oficinas de } \\
\text { confecção de } \\
\text { bijuterias } \\
\text { (atual)1 }\end{array}$ & - Nenhuma & $\begin{array}{c}\text { - Vôlei e futebol } \\
\text { (2002-2012) } \\
\text { - Nenhuma } \\
\text { (atualmente) }\end{array}$ \\
\hline
\end{tabular}

Percebe-se, ainda, que, no atendimento desenvolvido, desde a Granja Santana ao atual Centro Educacional Padre João Maria, deu-se ênfase a uma educação alternativa. Evidencia-se que a grande preocupação com o aperfeiçoamento da raça e ordenamento da nação, instituída nas primeiras ações para a infância e adolescência, desde a primeira república, e evidentemente a moralização da posição social das mulheres, reforçada pelos ensinamentos cristãos, foram utilizados como justificativas para afastar, no caso das meninas, a criança e a adolescente pobre de comportamentos que ameaçassem a opressão patriarcal.

É importante notar que, no âmbito do atendimento nas unidades femininas, observou-se, e ainda se observa, uma naturalização da opressão feminina relacionada à ideia da dimensão da família, em particular, no que corresponde aos cuidados e ao trabalho doméstico. Não obstante, algumas aulas denominadas pelos profissionais entrevistados por aulas de alfabetização, que visavam à instrução formal, restaram às adolescentes oficinas 
que, frequentemente, pautaram e ainda pautam as possibilidades educacionais do ponto de vista da inserção social e profissional nas responsabilidades domésticas e familiares.

No tocante à política de atendimento às crianças e adolescentes, apesar de textos institucionais e legislativos, como o SINASE, introduzirem princípios de igualdade entre os gêneros, esses avanços não têm tido efeito na prática. A partir dessa discussão, entende-se que o atendimento nas unidades de aplicação de medidas para adolescentes autoras de atos infracionais, o estado do $\mathrm{RN}$ desenvolveu uma versão feminina. Certamente, não pelos motivos que prezam pelo respeito às particularidades das meninas nesse contexto, mas pelo descaso, ao insistir em naturalizar aspectos que são da ordem da relação social entre os sexos.

\section{Considerações Finais}

Com base na análise dos dados foi possível apreender que as propostas educacionais que embasaram o atendimento no RN são reflexos dessa reprodução discriminatória sobre as adolescentes. Sabemos que, com o objetivo de prevenir que crianças e adolescentes considerados moralmente abandonados viessem a infringir as leis, o Estado, desde o início da república, propôs ocupar suas mentes. De acordo com Rizzini e Pilotti (2009), a ideia não era apenas prover a educação de crianças e adolescentes desvalidas e/ou menores, mas impor uma educação universal e racional condizente a formação do capital humano.

Como questão crucial para o desenvolvimento econômico do capitalismo, essa educação foi proporcionada a meninas e meninos pobres de forma divergente $\mathrm{e}$ hierarquizada. Com relação à adolescente em cumprimento de medida socioeducativa no
$\mathrm{RN}$, observou-se que houve e ainda há uma versão educacional feminina. No interior das unidades, são planejados e executados programas educativos que reforçam as construções sociais sobre as mulheres, mesmo após os avanços nos paradigmas de atendimento.

Ao longo da história da política de atendimento às adolescentes envolvidas com infrações no $\mathrm{RN}$, a representação do feminino foi dada como algo natural. Ao desenvolver-se a partir dessa perspectiva, o atendimento, nesses últimos trinta e cinco anos, deixou intacta a hierarquização existente na relação social entre os sexos. Segundo Carloto e Mariano (2010), a invisibilidade sobre a condição social das mulheres tem se incorporado no interior das políticas sociais.

Temos visto que as políticas sociais, em diversos âmbitos, não consideram as especificidades dos sujeitos de forma eficaz. Essa situação nos faz reconhecer que, embora a Política Nacional para Mulheres defenda ações de caráter universal, ao mesmo tempo, alerta para a necessidade de contemplar as demandas específicas das mulheres. Com base em Viana (2013), quando nos propomos a lutar pela implementação de políticas que respeitem de fato as necessidades das mulheres, essas devem ser direcionadas para a transformação das condições de vida das mulheres promovendo a construção da sua cidadania.

Dessa forma, no que concerne à política para a infância e adolescência, também é necessário que sejam pensadas ações que ultrapassem a cultura assistencialista e clientelista da assistência social brasileira, e que, em sua execução, busque-se novos impulsos e garantam as condições necessárias para a transformação social das condições de vida das adolescentes autoras de atos infracionais. Para alcance disto, concluímos que há a necessidade da 
produção de mais estudos que questionem a relação social entre os sexos e gêneros no campo da assistência para crianças e adolescentes, no intuito de contribuir com a construção de práticas que sejam equitativas e, simultaneamente, respeitem as necessidades básicas dos distintos gêneros. Para tanto, são necessárias formações que objetivem desenvolver o pensamento crítico sobre o contexto das adolescentes, como também sobre compreensão social e as vivências divergentes nas relações de gênero, com vistas a superar as práticas assistencialistas que reproduzem a subordinação das mulheres.

E, o mais essencial, é necessário que atuemos sempre a favor das questões das mulheres como forma de conseguir caminho para outro projeto de sociedade, definitivamente sem explorações. Entendemos que as relações de gênero se encontram dentro de um complexo social profundamente afetado pelo sistema do capital e que apenas a luta feminista não será capaz de sanar as discriminações seculares direcionadas às mulheres, mas é imprescindível, a partir de uma postura emancipatória, evidenciar a realidade de como a desigualdade social e a violação dos direitos das mulheres se desenvolvem de maneira especifica para o público feminino.

1 As reflexões dessa pesquisa tem por base a dissertação de mestrado "O atendimento às adolescentes autoras de atos infracionais no estado do Rio Grande do Norte" da autora Rocelly Dayane Teotonio da Cunha, sob a orientação da Prof ${ }^{a}$ Dra. Ilana Lemos de Paiva. A pesquisa esteve vinculada aos estudos do Observatório da População Infanto-juvenil em contextos de violência (OBIJUV) e ao Grupo de Pesquisa Marxismo \& Educação (GPM\&E), ambos vinculados ao Departamento de Pós-Graduação em Psicologia da Universidade Federal do Rio Grande do Norte (UFRN). Sendo defendida em agosto de 2014.
2 Utilizamos o termo prostituição para referenciarmos como a exploração sexual de adolescentes era tratada nos documentos oficiais da Fundação Estadual dos Direitos da Criança e do Adolescente (FUNDAC).

3 Segundo dados do Dieese (2001) são nas áreas de serviços pessoais, domésticos, administração pública, saúde, ensino, serviços, comunitários, comunicações, comércio de mercadorias ou atividades agrícolas que concentram a maior parte da mão de obra feminina.

4 O Inquérito Civil $\mathrm{n}^{\mathrm{o}} \quad 010 / 2012$ da $21^{\mathrm{a}}$ Promotoria de Justiça da Comarca de Natal, diz respeito a uma Ação Civil Pública com pedido de tutela de urgência em face das irregularidades verificadas na FUNDAC. Disponível em: http: www.mp.rn.gov.br/controle/file/2013.

Esse documento foi produzido pelo Ministério Público do Estado do Rio Grande do Norte, Defensoria Pública do Estado do Rio Grande do Norte, Tribunal de Justiça do Estado do Rio Grande do Norte, Corregedoria Geral de Justiça do Estado do Rio Grande do Norte, Ordem dos Advogados do Brasil Seccional do Rio Grande do Norte, Fórum Nacional dos Direitos da Criança e do Adolescente - Fórum DCA e Conselho Estadual dos Direitos da Criança e do Adolescente - CONSEC. Disponível em: http://www.mprn.mp.br/controle/file/2012_DOCUME NTO\%20INTERISTITUCIONAL_IRREGULARIDA DES_SINASE.pdf.

\section{Referências}

ANTUNES, Ricardo. Os sentidos do trabalho: ensaio sobre a afirmação e a negação do trabalho. $3^{\text {a }}$ edição. São Paulo: Boitempo, 1999.

ARANTES, Esther Maria de Magalhães. Rostos de Crianças no Brasil. In: RIZZINI, Irene; PILOTTI, Francisco. A arte de governar crianças: a história das políticas sociais, da legislação e da assistência à infância no Brasil. $2^{\mathrm{a}}$ edição. São Paulo: Cortez, 2009, p. 153-203.

ÁVILA, Maria Betânia de Melo. A dinâmica 
do trabalho produtivo e reprodutivo: uma contradição viva no cotidiano das mulheres. In: VENTURI, Gustavo; GODINHA, Tatau. Mulheres Brasileiras e Gênero nos espaços público e privado: uma década de mudanças na opinião pública. $1^{\text {a }}$ edição. São Paulo: Editora Fundação Perseu Abramo, 2013, p. 231-247.

BASÍLIO, Luiz Cavalieri; KRAMER, Sônia. Infância, Educação e Direitos Humanos. $4^{\mathrm{a}}$ edição. São Paulo: Cortez, 2011, pp. 83-106.

BEISIEGEL, Celso de Rui. Ensino público e educação popular. In CANESQUI, Ana Maria; PAIVA, Vanilda Pereira. Perspectivas e dilemas da Educação Popular. $1^{\text {a }}$ edição. Rio de Janeiro: Graal,1984, p. 128-139.

CARLOTO, Cássia Maria; MARIANO, Silvana Aparecida. No meio do caminho entre o privado e o público: um debate sobre o papel das mulheres na política de assistência social. Revista Estudos Feministas, v. 18, n. 352, p. 451- 471, 2008.

CENTRO EDUCACIONAL PADRE JOÃO MARIA. Histórico do Ceduc Padre João Maria. Natal/RN: Fundação Estadual dos Direitos da Criança e do Adolescente. $1^{\text {a }}$ edição. Rio Grande do Norte: Fundação Estadual dos Direitos da Criança do RN, 2009, p. 1-3.

COSTA, Antônio Carlos Gomes da. Educação pelo trabalho. $1^{\circ}$ edição. Rio de janeiro: Debate, 1984.

CONANDA. Sistema Nacional de Atendimento socioeducativo (SINASE). Brasília: Secretaria Especial dos Direitos Humanos. Conselho Nacional dos Direitos da Criança e do Adolescente, 2006.
CUNHA, Rocelly Dayane Teotonio da. O atendimento às adolescentes autoras de atos infracionais no Rio Grande do Norte, 2014. Dissertação de Mestrado. Universidade Federal do Rio Grande do Norte. Natal, Rio Grande do Norte, Brasil.

DIESSE. A situação do trabalho no Brasil na primeira década dos anos 2000. $1^{\text {a }}$ edição. São Paulo: Departamento Intersindical de Estatística e Estudos Socioeconômicos, 2012.

DIOGO, Maria Fernanda; COUTINHO, Maria Chalfina. A dialética da inclusão/exclusão e o trabalho feminino. Revista Interações, v. 9, n. 21, p. 121-142, 2006.

EVANGELISTA, Dalmo de Oliveira. Barreiras da sobrevivência: angústias e dilemas de jovens autores de atos infracionais pós-institucionalização. $1^{\text {a }}$ edição. Natal: Editora Universitária EDUFRN, 2011.

FACHINETTO, Rochelle. A 'Casa das Bonecas': um estudo de caso sobre a unidade de atendimento socioeducativo do Rio Grande do Sul, 2008. Dissertação de Mestrado. Universidade Federal do Rio Grande do Sul. Porto Alegre, Rio Grande do Sul, Brasil.

FONSECA, Telma Gurgel. Gênero, subjetividade e trabalho. $1^{\text {a }}$ edição. Petrópolis-Rio de Janeiro: Vozes, 2000.

HIRATA, Helena. Nova Divisão Sexual do Trabalho? Um olhar voltado para a empresa e a sociedade. $1^{\text {a }}$ edição. São Paulo: Boitempo Editorial, 2002. 
HIRATA, Helena; KERGOAT, Daniele. Novas configurações da divisão sexual do trabalho. Cadernos de Pesquisa, v. 37, n. 132, p. 595 - 609, 2007.

LOPES, Lorena da Silva; AZEVEDO, Renata Custodio; FROTA, Maria Helena de Paula. Há mais mulheres pobres que homens pobres? Reflexões sobre pobreza e gênero na América Latina. O público e o privado, v. 2, n. 8, p. $33-48,2006$.

MACHADO, Roberto; LOUREIRO, Ângela; LUZ, Rogério; MURICY, Kátia. Danação da norma: a medicina social e constituição da psiquiatria no Brasil. $1^{\text {a }}$ edição. Rio de Janeiro: Edições Graal, 1978.

MEIHY, João Carlos Sebe Bom. Manual de História Oral. $2^{a}$ edição. São Paulo: Edições Loyola, 1998.

MINELLA, Luzinete Simões. Papéis Sexuais e hierarquias de gênero na história social sobre infância no Brasil. Cadernos Pagu, v. 1, n. 26, p. 289 - 327, 2006.

OLIVEIRA, Maria. de Fátima. D de \& ARAÚJO, Maria. Vilani de (1979). Tentativa de uma análise da situação da menor carenciada-Instituto Padre João Maria. Monografia de Graduação, Natal/RN: UFRN.

OLIVEIRA, Walter. Educação Social de Rua: as bases políticas e pedagógicas para educação popular. Revista História, Ciências, Saúde, v. 14, n.1, p. 135 - 158, 2007.

RAGO, Margareth. Trabalho feminino e sexualidade. In: DEL PRIORE, Mary. História das mulheres no Brasil. $1^{a}$ edição. São Paulo: Contexto, 1997, p. 578- 606.
RIZZINI, Irene; PILOTTI, Francisco. A arte de governar crianças: a história das políticas sociais, da legislação e da assistência à infância no Brasil. $2^{\mathrm{a}}$ edição. São Paulo: Editora Cortez, 2009.

RIZZINI, Irma. A Assistência à Infância no Brasil: uma análise de sua construção. $1^{\text {a }}$ edição. Rio de Janeiro: Editora Universitária Santa Úrsula, 1993.

SAFFIOTI, Heleieth Iara Bongiovani. O poder do macho. $1^{\text {a }}$ edição. São Paulo: Editora Moderna, 1987.

SAFFIOTI, Heleieth Iara Bongiovani; ALMEIDA, Suely Souza de. Violência de gênero: poder e impotência. $1^{a}$ edição. Rio de Janeiro: Editora Revinter, 1995.

SAFIOTTI, Heleieth Iara Bongiovani. A Mulher na sociedade de classes: Mito e Realidade. $1^{a}$ edição. Rio de Janeiro: Editora Vozes, 1979.

SAFFIOTI, Heleieth Iara Bongiovani. Gênero, patriarcado, violência. $1^{a}$ edição. São Paulo: Fundação Perseu Abramo, 2004.

SILVA, Rita de Cássia Freire e Lima, Fátima Fernandes. Educação pelo Trabalho na instituição Padre João Maria. $1^{a}$ edição. Natal/RN: Editora da UFRN, 1986.

SILVA, Vera. Controlo e Punição: As prisões para mulheres. Associação Portuguesa de estudos sobre as mulheres, v. 1, n. 28 , p. 59 - 72, 2013.

SILVA, Geórgia Sibele Nogueira da Silva. A construção das vulnera(há)bilidades masculinas: uma questão de saúde e violência. In: PAIVA, Ilana Lemos de; BEZERRA, Marlos Alves; NASCIMENTO, SILVA, Géorgia Sibele Nogueira da Silva; 
0 atendimento às adolescentes em conflito com a lei: em foco as propostas educacionais no Rio

Grande do Norte

NASCIMENTO, Périsson Dantas do. Infância e Juventude: em contextos de vulnerabilidades. $1^{\text {a }}$ edição. São Paulo: Editora Zagodoni, 2013, p. 153 - 173.

WERTHEIN, Jorge. Educação de Adultos na América Latina. $1^{\text {a }}$ edição. Campinas: Papirus, 1985.

VIANA, Raquel. Desafios e limites das políticas públicas no cotidiano das mulheres. In: VENTURI, Gustavo; GODINHO, Tatau. Mulheres Brasileiras e Gênero nos espaços público e privado: uma década de mudanças na opinião pública. $1^{a}$ edição. São Paulo: Editora Fundação Perseu Abramo, 2013, p. 377 - 391.

VOGEL, Arno. Do Estado ao Estatuto: propostas e vicissitudes da política de atendimento à infância e adolescência no Brasil contemporâneo. In: RIZZINI, Irene; PILOTTI, Francisco. A arte de governar crianças: a história das políticas sociais, da legislação e da assistência à infância no Brasil. $2^{a}$ edição. São Paulo: Editora Cortez, 2009 , p. 287 - 329.

Recebido em 23 de julho de 2014. Aceito em 07 de maio de 2015. 